\title{
Health and Telework: New Challenges after COVID-19 Pandemic
}

\author{
Giuseppe Buomprisco ${ }^{1 *}$, Serafino Ricci ${ }^{1}$, Roberto Perri ${ }^{1}$, Simone De Sio ${ }^{1}$
}

${ }^{1}$ R.U. of Occupational Medicine, “Sapienza” University of Rome, Viale Regina Elena 336 - 00161, Rome, ITALY

*Corresponding Author: giuseppe.buomprisco@uniroma1.it

Citation: Buomprisco, G., Ricci, S., Perri, R. and De Sio, S. (2021). Health and Telework: New Challenges after COVID-19 Pandemic. European Journal of Environment and Public Health, 5(2), em0073. https://doi.org/10.21601/ejeph/9705

ARTICLE INFO

Received: 9 Oct. 2020

Accepted: 21 Nov. 2020

\begin{abstract}
The COVID-19 pandemic represented a big challenge not only for the health systems but also for the working world that has been characterized by the spread of telework. The aim of this review is to resume the knowledge about the effects of telework on the health and safety of teleworkers, and to point out these implications in the light of the growing development and diffusion of it after COVID-19 pandemic. A literature research on the main scientific research engines (Pubmed, Scopus, Google Scholar, Cochrane Review) has been performed. No restrictions were applied for language or publication type. All the articles not concerned with the health effects of telework have been excluded. That kind of work arrangement can take advantages to both employers and workers by improving productivity and work-life balance. However, it has some potential disadvantages, represented by the possible negative implications on worker's health. The main hazards for the health of teleworkers are: the unavailability of ergonomic work equipment and a dedicated working area, the risk of overwork, and psychosocial implications of working from home. Performing telework can affect both physical and psychosocial health but some authors also described potential health benefits.
\end{abstract}

Keywords: telework, health, telecommuting, work-from-home, remote work, COVID-19 pandemic

\section{INTRODUCTION}

The COVID-19 pandemic, at the beginning of 2020, represented a big challenge not only for the health systems but also for the working world. On the one hand, it stressed the maintenance of health systems, but on the other, it represented a driving force for the modernization of work as a whole. An example of that is represented by the spread of telework or telecommuting, made possible also by the current level of development and diffusion of telecommunication systems, especially in industrialized countries. The adoption of this kind of working organization, in fact, is fundamental during the actual pandemic, in order to allow social distancing in workplaces (Cahapay, 2020). Indeed, many clusters of infection have been reported in plants where the employees worked in close proximity, with physical exertion and fast work paces (Cohen, 2020).

Even if this concept dates back to the 70s, when the oil crisis has led to rethinking the work arrangements (increasingly dependent on the movement of workers to the workplace), there is still no consensus on its exact definition. That is also demonstrated by the many kinds of terms applied to it: telework, telecommuting, remote work, work-fromhome, smart working, e-work etc. The 2002 European Framework Agreement on Telework, defined it as " $A$ form of organizing and/or performing work, using information technology, in the context of an employment contract/relationship, where work, which could also be performed at the employer's premises, is carried out away from those premises on a regular basis." The International Labor Office (ILO) also defined a "teleworker" as "any ICT-using employee working outside of the main office on at least one occasion each month to perform work-related tasks" (Eurofound and the ILO, 2017).

In recent years, the adoption of teleworking has been increasingly implemented all over the world. In the US, according to the analysis of data from the US Census Bureau, the non-self-employed population of teleworkers grew by $102 \%$ from 2005 to 2014, counting 3.7 million employees, especially in the public sector (Lister and Harnish, 2011). In Europe, the European Working condition Survey of 2015, reported that around one-fifth of workers did some form of telework or Information and Communications Technologies (ICT)-based mobile work, with many differences between the Member States. Italy recorded just $8 \%$ of workers doing telework/ICT-based mobile work, Germany the 11\%, France the $23 \%$, whereas in the Northern Countries those rates were higher, with Denmark counting the $36 \%$ of teleworkers. Those differences are probably due to the different Country's affinity for technology, the availability and quality of ICT infrastructure, management culture, and companies' involvement. 
Table 1. Benefits and disadvantages of telework for the company and for workers

\begin{tabular}{|c|c|c|c|}
\hline WORKERS & & COMPANY & \\
\hline ADVANTAGES & DISADVANTAGES & ADVANTAGES & DISADVANTAGES \\
\hline $\begin{array}{l}\text { Reduction of the time dedicated } \\
\text { to commute }\end{array}$ & $\begin{array}{l}\text { Less visibility and career } \\
\text { opportunities }\end{array}$ & Increased productivity & Difficulty in managing distant workers \\
\hline $\begin{array}{l}\text { Work according to own } \\
\text { availability and Biorhythms }\end{array}$ & $\begin{array}{l}\text { Isolation, reduction of external } \\
\text { relational life }\end{array}$ & $\begin{array}{l}\text { Reduction of costs and } \\
\text { company size }\end{array}$ & $\begin{array}{l}\text { Cultural reorganization of business } \\
\text { processes }\end{array}$ \\
\hline More free time & Invasion of the private sphere & $\begin{array}{l}\text { Increased employee } \\
\text { motivation }\end{array}$ & $\begin{array}{l}\text { Several employment contracts to } \\
\text { manage }\end{array}$ \\
\hline Control by objectives & $\begin{array}{l}\text { Greater difficulties in participating } \\
\text { in trade union activities }\end{array}$ & $\begin{array}{l}\text { Reduction in the number and } \\
\text { role of middle managers }\end{array}$ & Conflict with the middle leaders \\
\hline $\begin{array}{l}\text { Increased closeness to family } \\
\text { and friends }\end{array}$ & $\begin{array}{l}\text { Unsecured safety and work } \\
\text { standards }\end{array}$ & $\begin{array}{l}\text { Lower costs for the rental of } \\
\text { properties }\end{array}$ & $\begin{array}{l}\text { Higher expenses for telecommunication } \\
\text { equipment and training }\end{array}$ \\
\hline Free choice of where to live & $\begin{array}{l}\text { Reduction of the spatial distinction } \\
\text { between home and office }\end{array}$ & $\begin{array}{l}\text { Greater organizational } \\
\text { flexibility }\end{array}$ & Discussion of the business organization \\
\hline
\end{tabular}

Looking at the demographic characteristics of teleworkers in Europe, it emerges that male employees are generally more likely to do telework than females. Those gender differences can be due to the different sectors (e.g., real estate and finance) and occupations that most implemented the use of telework, whose workforce is mainly represented by men. In general, teleworkers are younger than their office-based counterparts, often they have a high educational qualification, and they live in urban areas (Welz and Wolf, 2010). One fifth of workers that telecommute is self-employed while the rest are employees (Eurofound, 2020).

Table 1 resumes the benefits and the disadvantages of telework both for the company and for workers.

The aim of this short review is to resume the knowledge about the effects of telework on the health and safety of teleworkers, in the light of the growing development and diffusion of that form of work arrangement after COVID-19 pandemic.

\section{METHODS}

A literature research on the main scientific research engines (Pubmed, Scopus, Google Scholar, Cochrane Review) has been performed. No restrictions were applied for language or publication type. All the articles not concerned with the health effects of telework have been excluded. Articles published prior to 1990, editorial articles and individual contributions (i.e., conferences' speech), have been also excluded.

The search strategy used a combination of controlled vocabulary and free text terms based on the following keywords: telework, telecommuting, worker's health, remote work, work-from-home, occupational health, effects, impacts. The search has been made from September 1, 2020 to September 31, 2020.

\section{RESULTS}

\section{Health Hazards Linked to Telework}

Most part of the jobs that can be performed out of the employer's premises requires a telecommunication system, mainly represented by personal computers, tablets or smartphone. In Europe, the Display Screen Directive $90 / 270 / \mathrm{EEC}$, firstly tried to rule the minimum safety and health requirements for work with display screen equipment, giving the member countries the general guidelines for the protection of workers' health. It is known, in fact, that exposure to the Visual Display Terminal (VDT), can affect many aspects of workers' health, mainly causing visual discomfort and musculoskeletal pain (Aarås et al., 2000). Neck/shoulders pain and, overall, low back pain, are the main musculoskeletal symptoms reported (Riccò et al., 2016) but they can be relieved from the use of ergonomic workstations and from worker training and information programs (Ketola et al., 2002).

Another threat to workers' health, outside the usual workplace, can be represented by the microclimate. The place where the worker telecommutes, could not have air conditioning or circulating systems that can ensure good local atmospheric conditions. That can represent a problem for the employer's responsibilities on worker's health care. The exposure to low perceived air quality and humidity can lead to sensory irritation symptoms in the eyes and airways (in particular for workers suffering from asthma or chronic obstructive pulmonary diseases), low work performance, skin problems, headache, tiredness, and low sleep quality (Wolkoff, 2018). Those symptoms can refer to the so-called "sick building syndrome", and, for people working from home, to its counterpart "sick home syndrome" (Runeson-Broberg and Norbäck, 2013).

Other hazards for the health of teleworkers are represented by psychosocial ones. They derive from the intrinsic nature of telework which, for example, does not allow any direct socialwork interaction with colleagues or superiors. This condition can, in fact, generate feelings of loneliness, isolation, poor mental health (e.g., anxiety, depression, stress, etc.) (Mann and Holdsworth, 2003). In addition, work-family interaction as well as work-life balance (i.e., the equilibrium between time allocated for work and other aspects of life such as personal interests, self -care, family and social or leisure activities), can contribute to influencing mental health (in a positive or negative way) (Gálvez et al., 2011).

In the most part of developed countries, the employer must ensure the supply of suitable and ergonomic work equipment, the safety and comfort (e.g., in terms of lightning, cleaning, microclimate etc.) of workplaces and the health surveillance of employees (e.g., periodic vision tests and functional evaluation of the spine). Those obligations serve to ensure the 
worker the highest possible level of health and safety at work. Private homes could not ensure those measures, thus exposing teleworkers to the above-mentioned hazards.

\section{Health Implications of Telework}

Performing telework, which implies the continuous use of ICTs and VDTs, can affect several aspects of personal health (Nakazawa et al., 2002). The health problems associated with telework can be, therefore, grouped into two big categories: physical and psychosocial. Some authors also described potential health benefits of telework.

\section{Physical Problems}

It has been widely demonstrated that using personal computers at work, especially if carried out on non-ergonomic workstations, increase the risk of musculoskeletal disorders (MSDs), particularly upper limb disorders, lower limb disorders and back pain (Hoe et al, 2012; Jensen et al., 2002; Wahlström, 2005). The factors that are linked with this risk are: awkward postures, repetitive movements and long period of continuous work (teleworkers can't socialize and thus don't allow to take health breaks, that can be useful for musculoskeletal relaxation (Skov et al., 1996). Teleworking is linked with an increased rate of physical inactivity and sedentarism both well-known determinants for health (Kurland and Bailey, 1999). In fact, they can contribute to the burden of chronic diseases, like diabetes, cardiovascular diseases (CVDs), obesity and hypertension (González et al., 2017).

\section{Psychosocial Problems}

The main mental problems linked to the experience of telework are sleeping disorders, work-related stress (Thomée et al., 2007). Social isolation is another possible consequence of telework, and a negative loop has been suggested (MorahanMartin and Schumacher, 2003).

Work-related stress (WRS) is a complex phenomenon and develops when multiple psychosocial risk factors coexist and interact. Psychosocial risks arise from the interaction from work content, work organization, technological and environmental conditions, and workers' skills, resources, and needs. The factors that most influence the perception of stress are: excessive workloads, a lack of decisional autonomy, a lack of support by colleagues or superiors, relational conflicts in the workplace, a low consideration of one's role within the company, and a lack of involvement in the changes of company organization (De Sio et al., 2018). Some of these (high workloads, low involvement, low role's consideration, lack of support) can be experienced by teleworkers, thus causing work-related stress. Occupational stress is linked with several health problems including anxiety, depression, suicide attempts, sleep disorders, back pain, chronic fatigue, digestive problems, autoimmune diseases, impaired immune function, cardiovascular diseases, hypertension, and peptic ulcers (Schneiderman et al., 2005).

\section{Health Benefits}

The benefits of teleworking have been described by many authors but they're mostly practical than health related. Increased flexibility and better work-life balance (Mann et al., 2000) are often accompanied by increased productivity
(Montreuil and Lippel, 2003). Other benefits include reduced commuting time, increased opportunity for workers to focus on their work tasks away from the distractions of the office, a more flexible schedule for workers and the freedom to work from an alternative location, away from the premise of the employer. In addition, part-time and occasional teleworking may reduce forms of violence and harassment requiring faceto-face contact (ILO, 2020).

Other aspects that may have non-negligible importance in terms of public health are those relating to transports, air quality (inside as well as outside), consumption of energy and materials, etc. that will benefit from the fewer workers forced to travel to work.

\section{DISCUSSION}

Telework is a kind of work arrangement that especially after COVID-19 Pandemic, will be more and more adopted worldwide. Telecommuting has many positive aspects both for workers and for employers. The former appreciate that it improves their work-life balance, increase their free time, and give them more autonomy and flexibility. The latter can reduce business costs and have more productivity by the employees. In addition, this kind of work arrangement can be suitable for a variety of works and for people of different ages, gender, and health status (i.e., people with motor disabilities).

In light of the increasing spread of teleworking, which will probably continue to grow even after the end of the COVID-19 pandemic, it is essential to put in place preventive measures against the health risks deriving from this form of work organization.

In terms of occupational health and safety issues for teleworkers, as previously discussed, the two most recognized issues are psychosocial and posture ergonomics risks. Working from home during the COVID-19 pandemic is an abnormal condition, that forces workers at home for a prolonged period, under difficult external circumstances. That is causing high levels of anxiety due to the health, social and economic implications of the crisis (ILO, 2020).

The International Labour Office, in its ad hoc document drawn up in 2020, during the COVID-19 pandemic, it provided a series of useful recommendations to prevent the health risks deriving from telework (Table 2).

\section{CONCLUSION}

There are very few works exploring the relationships between telework and its health effects. Occupational doctors worldwide will face emerging workers' health problems linked to telework, this short review intends to contribute to stimulating research in this area, that will be more and more important in the future. 
Table 2. Occupational Safety and Health Policies for teleworkers

- Inform the employers about the health and safety risks and hazards, the home office environment, equipment, ergonomics, and stress as well as other mental health issues.

- Provide OSH and ergonomic protocols specifically designed for teleworkers.

- Train managers and teleworkers on the importance of taking sufficient rest breaks during the workday, as well as clarifying that such breaks won't have negative career consequences.

- Promote physical health, including exercise, and encourage workers to maintain healthy eating habits.

- Provide psychological support for workers to share their fears and worries confidentially (helplines, counseling, support groups).

- Provide to workers appliances compatible with ergonomic standards.

\section{REFERENCES}

Aarås, A., Horgen, G. and Ro, O. (2000) Work With the Visual Display Unit: Health Consequences. International Journal of Human-Computer Interaction, 12(1), 107-134. https://doi.org/10.1207/S15327590IJHC1201_5

Cahapay, M. B. (2020). Social Distancing Practices of Residents in a Philippine Region with Low Risk of COVID-19 Infection. European Journal of Environment and Public Health, 4(2), em0057. https://doi.org/10.29333/ejeph/8455

Cohen, P. N. (2020). The COVID-19 Epidemic in Rural U.S. Counties. European Journal of Environment and Public Health, 4(2), em0050. https://doi.org/10.29333/ejeph/8331

De Sio, S., Cedrone, F., Trovato Battagliola, E., Buomprisco, G., Perri, R. and Greco, E. (2018) The Perception of Psychosocial Risks and Work-Related Stress in Relation to Job Insecurity and Gender Differences: A Cross-Sectional Study. BioMed research international, 2018, 7649085. https://doi.org/10.1155/2018/7649085

Eurofound (2020). Telework and ICT-based mobile work: Flexible working in the digital age, New forms of employment series. Publications Office of the European Union, Luxembourg.

Eurofound and the ILO. (2017). Working anytime, anywhere: The effects on the world of work. Publications Office of the European Union, Luxembourg, and the International Labour Office, Geneva.

Gálvez, A., Martinez-Argüelles, M. and Pérez, C. (2011). Telework and Work-Life Balance: Some Dimensions for Organisational Change. Journal of Workplace Rights, 16(34), 273-297. https://doi.org/10.2190/WR.16.3-4.b

González, K., Fuentes, J. and Márquez, J. L. (2017). Physical Inactivity, Sedentary Behavior and Chronic Diseases. Korean journal of family medicine, 38(3), 111-115. https://doi.org/10.4082/kjfm.2017.38.3.111

Hoe, V., Urquhart, D., Kelsall, H. and Sim, M. (2012). Ergonomic design and training for preventing work-related musculoskeletal disorders of the upper limb and neck in adults (Review). Cochrane Database of Systematic Reviews, 8, Article No: CD008570. https://doi.org/10.1002/ 14651858.CD008570.pub2

ILO. (2020). Practical Guide on Teleworking during the COVID19 pandemic and beyond. A practical guide. Geneva: International Labour Office.

Irwin, F. (2004). Gaining the air quality and climate benefit for telework. World Resources Institute. Available at: http://goo.gl/IvdkU
Jensen, C., Finsen, L., Søgaard, K. and Christensen, H. (2002). Musculoskeletal symptoms and duration of computer and mouse use. International Journal Industrial Ergonomics, 30(4-5), 265-275. https://doi.org/10.1016/S0169-8141(02) 00130-0

Ketola, R., Toivonen, R., Häkkänen, M., Luukkonen, R., Takala, E. P. and Viikari-Juntura, E. (2002). Effects of ergonomic intervention in work with video display units. Scandinavian Journal of Work, Environment \& Health, 28(1), 18-24. https://doi.org/10.5271/sjweh.642

Kurland, N. B. and Bailey, D. E. (1999). Telework the advantages and challenges of working here, there, anywhere and anytime. Organization Dynamics, 28(2), 5368. https://doi.org/10.1016/S0090-2616(00)80016-9

Lister, K. and Harnish, T. (2011). The state of telework in the $U$. S.: How individuals, business, and government benefit. San Diego, CA: Telework Research Network.

Mann, S. and Holdsworth, L. (2003). The psychological impact of teleworking: stress, emotions and health. New Technology, Work and Employment, 18(3), 196-211. https://doi.org/10.1111/1468-005X.00121

Mann, S., Varey, R. and Button, W. (2000). An Exploration of the Emotional Impact of TeleWorking. Journal of Managerial Psychology, 15(7), 668-690. https://doi.org/10.1108/02683940010378054

Montreuil, S. and Lippel, K. (2003). Telework and Occupational Health: A Quebec Empirical Study and Regulatory Implications. Safety Science, 41(4), 339-358. https://doi.org/10.1016/S0925-7535(02)00042-5

Morahan-Martin, J. and Schumacher, P. (2003). Loneliness and social uses of the Internet. Computer Human Behavior, 19(6), 659-671. https://doi.org/10.1016/S0747-5632(03) 00040-2

Nakazawa, T., Okubo, Y., Suwazono, Y., Kobayashi, E., Komine, S., Kato, N. and Nogawa, K. (2002). Association between duration of daily VDT use and subjective symptoms. American Journal of Industrial Medicine, 42, 421426. https://doi.org/10.1002/ajim.10133

Riccò, M., Cattani, S., Gualerzi, G. and Signorelli, C. (2016). Use of Visual Display Units and work-related musculoskeletal complaints: a cross-sectional study. Medycyna pracy, 67(6), 707-719. https://doi.org/10.13075/mp.5893.00471 
Runeson-Broberg, R. and Norbäck, D. (2013). Sick building syndrome (SBS) and sick house syndrome (SHS) in relation to psychosocial stress at work in the Swedish workforce. International Archives of Occupational and Environmental Health, 86(8), 915-922. https://doi.org/10.1007/s00420012-0827-8

Schneiderman, N., Ironson, G. and Siegel, S. D. (2005). Stress and health: psychological, behavioral, and biological determinants. Annual review of clinical psychology, 1(1), 607-628. https://doi.org/10.1146/annurev.clinpsy.1.10280 3.144141

Skov, T., Borg, V. and Orhede, E. (1996). Psychosocial and physical risk factors for musculoskeletal disorders of the neck, shoulders, and lower back in salespeople. Occupational Environmental Medicine, 53, 351-356. https://doi.org/10.1136/oem.53.5.351
Thomée, S., Eklöf, M., Gustafsson, E., Nilsson, R. and Hagberg, M. (2007). Prevalence of perceived stress, symptoms of depression and sleep disturbances in relation to information and communication technology (ICT) use among young adults. An explorative prospective study. Computers in Human Behavior, 23(3), 1300-1321. https://doi.org/10.1016/j.chb.2004.12.007

Wahlström, J. (2005). Ergonomics, musculoskeletal disorders and computer work. Occupational Medicine, 55(3), 168-176. https://doi.org/10.1093/occmed/kqi083

Welz, C. and Wolf, F. (2010). Telework in the European Union. Eurofund. Dublin Ireland. Available at: https://www.eurofound.europa.eu/sites/default/files/ef_fil es/docs/eiro/tn0910050s/tn0910050s.pdf

Wolkoff, P. (2018). Indoor air humidity, air quality, and health - An overview. International Journal of Hygiene and Environmental Health, 221(3), 376-390. https://doi.org/ 10.1016/j.ijheh.2018.01.015 